\title{
Fixed point theorems for $\alpha$-Geraghty contraction type maps in metric spaces
}

\author{
Seong-Hoon Cho', Jong-Sook Bae² and Erdal Karapınar ${ }^{3 *}$
}

\section{*Correspondence:}

erdalkarapinar@yahoo.com

${ }^{3}$ Department of Mathematics, Atilim

University, Ankara, 06836, Turkey

Full list of author information is

available at the end of the article

\begin{abstract}
In this paper, we introduce a notion of $\alpha$-Geraghty contraction type maps in the setting of a metric space. We also establish some fixed point theorems for such maps and give an example to illustrate our results. Finally, we discuss the application of our main results in the research fields of ordinary differential equations.

MSC: $47 \mathrm{H} 10 ; 54 \mathrm{H} 25$

Keywords: fixed point; contraction type mapping; $\alpha$-Geraghty contraction type map; metric space
\end{abstract}

\section{Introduction and preliminaries}

The Banach contraction principle [1], which is a useful tool in the study of many branches of mathematics and mathematical sciences, is one of the earlier and fundamental results in fixed point theory. Because of its importance in nonlinear analysis, a number of authors have improved, generalized and extended this basic result either by defining a new contractive mapping in the context of a complete metric space or by investigating the existing contractive mappings in various abstract spaces; see, e.g., [2-10] and references therein.

In particular, Geraghty [6] obtained a generalization of the Banach contraction principle in the setting of complete metric spaces by considering an auxiliary function. Later, AminiHarandi and Emami [3] characterized the result of Geraghty in the context of a partially ordered complete metric space. This result is of particular interest since many real world problems can be identified in a partially ordered complete metric space. Cabellero et al. [11] discussed the existence of a best proximity point of Geraghty contraction.

Recently, Samet et al. [12] obtained remarkable fixed point results by defining the notion of $\alpha-\psi$-contractive mappings. The authors of [12] concluded also that several existing results can be obtained as consequences of their main results. Very recently, Karapinar and Samet [13] introduced the concept of generalized $\alpha-\psi$ contractive mappings, which was inspired by the notion of $\alpha-\psi$-contractive mappings. Furthermore, they [13] obtained some fixed point theorems for such mappings and listed some of the consequences of their main results.

In this paper, motivated by the developments discussed above, we define the concept of $\alpha$-Geraghty contraction type maps in the setting of a metric space. Moreover, we prove the existence and uniqueness of a fixed point of such maps in the context of a complete metric space. We give an example to illustrate our main theorem and consider an application of our result in the area of ordinary differential equations.

○2013 Cho et al.; licensee Springer. This is an Open Access article distributed under the terms of the Creative Commons Attribution License (http://creativecommons.org/licenses/by/2.0), which permits unrestricted use, distribution, and reproduction in any medium, provided the original work is properly cited. 
For the sake of completeness, we recollect some basic definitions and remarkable results on the topic in the literature.

Definition 1.1 [12] Let $T: X \rightarrow X$ be a map and $\alpha: X \times X \rightarrow \mathbb{R}$ be a function. Then $T$ is said to be $\alpha$-admissible [12] if

$$
\alpha(x, y) \geq 1 \quad \text { implies } \quad \alpha(T x, T y) \geq 1 .
$$

Definition 1.2 [13] An $\alpha$-admissible map $T$ is said to be triangular $\alpha$-admissible if

$$
\alpha(x, z) \geq 1 \quad \text { and } \quad \alpha(z, y) \geq 1 \quad \text { imply } \quad \alpha(x, y) \geq 1 .
$$

For more details for an $\alpha$-admissible map and a triangular $\alpha$-admissible map, see [12] and $[13,14]$, respectively.

Lemma 1.1 [13] Let $T: X \rightarrow X$ be a triangular $\alpha$-admissible map. Assume that there exists $x_{1} \in X$ such that $\alpha\left(x_{1}, T x_{1}\right) \geq 1$. Define a sequence $\left\{x_{n}\right\}$ by $x_{n+1}=T x_{n}$. Then we have $\alpha\left(x_{n}, x_{m}\right) \geq 1$ for all $m, n \in \mathbb{N}$ with $n<m$.

We denote by $\mathcal{F}$ the family of all functions $\beta:[0, \infty) \rightarrow[0,1)$ which satisfies the condition

$$
\lim _{n \rightarrow \infty} \beta\left(t_{n}\right)=1 \text { implies } \lim _{n \rightarrow \infty} t_{n}=0 .
$$

By using such maps, Geraghty [6] observed the following interesting results.

Theorem 1.1 [6] Let $(X, d)$ be a metric space, and let $T: X \rightarrow X$ be a map. Suppose that there exists $\beta \in \mathcal{F}$ such that for all $x, y \in X$,

$$
d(T x, T y) \leq \beta(d(x, y)) d(x, y) .
$$

Then $T$ has a unique fixed point $x_{*} \in X$, and $\left\{T^{n} x\right\}$ converges to $x_{*}$ for each $x \in X$.

\section{Fixed point theorems}

Let $(X, d)$ be a metric space, and let $\alpha: X \times X \rightarrow \mathbb{R}$ be a function. A map $T: X \rightarrow X$ is called a generalized $\alpha$-Geraghty contraction type map if there exists $\beta \in \mathcal{F}$ such that for all $x, y \in X$,

$$
\alpha(x, y) d(T x, T y) \leq \beta(M(x, y)) M(x, y)
$$

where $M(x, y)=\max \{d(x, y), d(x, T x), d(y, T y)\}$.

Remark 2.1 Since the functions belonging to $\mathcal{F}$ are strictly smaller than one, condition (3) implies that

$$
d(T x, T y)<M(x, y) \quad \text { for any } x, y \in X \text { with } x \neq y .
$$


Theorem 2.1 Let $(X, d)$ be a complete metric space, $\alpha: X \times X \rightarrow \mathbb{R}$ be a function, and let $T: X \rightarrow X$ be a map. Suppose that the following conditions are satisfied:

(1) $T$ is a generalized $\alpha$-Geraghty contraction type map;

(2) $T$ is triangular $\alpha$-admissible;

(3) there exists $x_{1} \in X$ such that $\alpha\left(x_{1}, T x_{1}\right) \geq 1$;

(4) $T$ is continuous.

Then $T$ has a fixed point $x_{*} \in X$, and $T$ is a Picard operator, that is, $\left\{T^{n} x_{1}\right\}$ converges to $x_{*}$.

Proof Let $x_{1} \in X$ be such that $\alpha\left(x_{1}, T x_{1}\right) \geq 1$. Define a sequence $\left\{x_{n}\right\} \subset X$ by $x_{n+1}=T x_{n}$ for $n \in \mathbb{N}$. If $x_{n_{0}}=x_{n_{0}+1}$ for some $n_{0} \in \mathbb{N}$, then $x_{n_{0}}$ is a fixed point of $T$, and hence the proof is completed. Thus, throughout the proof, we assume that $x_{n} \neq x_{n+1}$ for all $n \in \mathbb{N}$.

By Lemma 1.1, we have

$$
\alpha\left(x_{n}, x_{n+1}\right) \geq 1
$$

for all $n \in \mathbb{N}$. Then we have

$$
\begin{aligned}
d\left(x_{n+1}, x_{n+2}\right) & =d\left(T x_{n}, T x_{n+1}\right) \\
& \leq \alpha\left(x_{n}, x_{n+1}\right) d\left(T x_{n}, T x_{n+1}\right) \\
& \leq \beta\left(M\left(x_{n}, x_{n+1}\right)\right) M\left(x_{n}, x_{n+1}\right),
\end{aligned}
$$

for all $n \in \mathbb{N}$, where

$$
\begin{aligned}
M\left(x_{n}, x_{n+1}\right) & =\max \left\{d\left(x_{n}, x_{n+1}\right), d\left(x_{n}, T x_{n}\right), d\left(x_{n+1}, T x_{n+1}\right)\right\} \\
& =\max \left\{d\left(x_{n}, x_{n+1}\right), d\left(x_{n}, x_{n+1}\right), d\left(x_{n+1}, x_{n+2}\right)\right\} .
\end{aligned}
$$

Regarding the definition of $\beta$, the case $M\left(x_{n}, x_{n+1}\right)=d\left(x_{n+1}, x_{n+2}\right)$ is impossible. Indeed,

$$
\begin{aligned}
d\left(x_{n+1}, x_{n+2}\right) & \leq \beta\left(M\left(x_{n}, x_{n+1}\right)\right) M\left(x_{n}, x_{n+1}\right) \\
& \leq \beta\left(d\left(x_{n+1}, x_{n+2}\right)\right) d\left(x_{n+1}, x_{n+2}\right)<d\left(x_{n+1}, x_{n+2}\right),
\end{aligned}
$$

a contradiction.

Thus, we conclude that $d\left(x_{n+1}, x_{n+2}\right)<d\left(x_{n}, x_{n+1}\right)$ for all $n \in \mathbb{N}$. So, the sequence $\left\{d\left(x_{n}, x_{n+1}\right)\right\}$ is nonnegative and nonincreasing. Hence, there exists $r \geq 0$ such that $\lim _{n \rightarrow \infty} d\left(x_{n}, x_{n+1}\right)=r$. We claim that $r=0$. Suppose, on the contrary, that $r>0$. Then, due to (5), we have

$$
\frac{d\left(x_{n+1}, x_{n+2}\right)}{d\left(x_{n}, x_{n+1}\right)} \leq \beta\left(d\left(x_{n}, x_{n+1}\right)\right)<1
$$

which yields that $\lim _{n \rightarrow \infty} \beta\left(d\left(x_{n}, x_{n+1}\right)\right)=1$. Since $\beta \in \mathcal{F}$, we derive that

$$
\lim _{n \rightarrow \infty} d\left(x_{n}, x_{n+1}\right)=0 .
$$

We shall show that $\left\{x_{n}\right\}$ is a Cauchy sequence. Suppose, on the contrary, that $\left\{x_{n}\right\}$ is not a Cauchy sequence. Thus, there exists $\epsilon>0$ such that, for all $k>0$, there exist $m(k)>n(k)>k$ 
with (the smallest number satisfying the condition below)

$$
d\left(x_{m(k)}, x_{n(k)}\right) \geq \epsilon \quad \text { and } \quad d\left(x_{m(k)-1}, x_{n(k)}\right)<\epsilon .
$$

Then we have

$$
\begin{aligned}
\epsilon & \leq d\left(x_{m(k)}, x_{n(k)}\right) \\
& \leq d\left(x_{m(k)}, x_{m(k)-1}\right)+d\left(x_{m(k)-1}, x_{n(k)}\right) \\
& <d\left(x_{m(k)}, x_{m(k)-1}\right)+\epsilon
\end{aligned}
$$

Letting $k \rightarrow \infty$ in the above inequality, we have

$$
\lim _{k \rightarrow \infty} d\left(x_{m(k)}, x_{n(k)}\right)=\epsilon
$$

By using (6) and (7), we obtain $\lim _{k \rightarrow \infty} d\left(x_{m(k)-1}, x_{n(k)-1}\right)=\epsilon$.

By Lemma 1.1, $\alpha\left(x_{n(k)-1}, x_{m(k)-1}\right) \geq 1$. Thus we have

$$
\begin{aligned}
& d\left(x_{m(k)}, x_{n(k)}\right) \\
& \quad=d\left(T x_{m(k)-1}, T x_{n(k)-1}\right) \\
& \quad \leq \alpha\left(x_{n(k)-1}, x_{m(k)-1}\right) d\left(T x_{n(k)-1}, T x_{m(k)-1}\right) \\
& \quad \leq \beta\left(M\left(x_{n(k)-1}, x_{m(k)-1}\right)\right) M\left(x_{n(k)-1}, x_{m(k)-1}\right),
\end{aligned}
$$

where

$$
\begin{aligned}
M\left(x_{n(k)-1}, x_{m(k)-1}\right) & =\max \left\{d\left(x_{n(k)-1}, x_{m(k)-1}\right), d\left(x_{n(k)-1}, T x_{n(k)-1}\right), d\left(x_{m(k)-1}, T x_{m(k)-1}\right)\right\} \\
& =\max \left\{d\left(x_{n(k)-1}, x_{m(k)-1}\right), d\left(x_{n(k)-1}, x_{n(k)}\right), d\left(x_{m(k)-1}, x_{m(k)}\right)\right\} .
\end{aligned}
$$

Hence, we conclude that

$$
\frac{d\left(x_{m(k)}, x_{n(k)}\right)}{M\left(x_{n(k)-1}, x_{m(k)-1}\right)} \leq \beta\left(M\left(x_{n(k)-1}, x_{m(k)-1}\right)\right) .
$$

Keeping (6) in mind and letting $n \rightarrow \infty$ in the above inequality, we derive that $\lim _{k \rightarrow \infty} \beta\left(d\left(x_{n(k)-1}, x_{m(k)-1}\right)\right)=1$, and so $\lim _{k \rightarrow \infty} d\left(x_{n(k)-1}, x_{m(k)-1}\right)=0$. Hence, $\epsilon=0$, which is a contradiction. So, we conclude that $\left\{x_{n}\right\}$ is a Cauchy sequence. It follows from the completeness of $X$ that there exists

$$
x_{*}=\lim _{n \rightarrow \infty} x_{n} \in X
$$

Since $T$ is continuous, we get $\lim _{n \rightarrow \infty} x_{n}=T x_{*}$, and so $x_{*}=T x_{*}$, which completes the proof.

The continuity of the mapping $T$ can be dropped. In the following theorem, we replace the continuity of the operator $T$ by a suitable condition. 
Theorem 2.2 Let $(X, d)$ be a complete metric space, $\alpha: X \times X \rightarrow \mathbb{R}$ be a function, and let $T: X \rightarrow X$ be a map. Suppose that the following conditions are satisfied:

(1) $T$ is a generalized $\alpha$-Geraghty contraction type map;

(2) $T$ is triangular $\alpha$-admissible;

(3) there exists $x_{1} \in X$ such that $\alpha\left(x_{1}, T x_{1}\right) \geq 1$;

(4) if $\left\{x_{n}\right\}$ is a sequence in $X$ such that $\alpha\left(x_{n}, x_{n+1}\right) \geq 1$ for all $n$ and $x_{n} \rightarrow x \in X$ as $n \rightarrow \infty$, then there exists a subsequence $\left\{x_{n(k)}\right\}$ of $\left\{x_{n}\right\}$ such that $\alpha\left(x_{n(k)}, x\right) \geq 1$ for all $k$.

Then $T$ has a fixed point $x_{*} \in X$, and $T$ is a Picard operator, that is, $\left\{T^{n} x_{1}\right\}$ converges to $x_{*}$.

Proof Following the lines in the proof of Theorem 2.1, we conclude that the sequence $\left\{x_{n}\right\}$, defined by $x_{n+1}=T x_{n}$ for all $n \geq 0$, converges to $x_{*} \in X$. Regarding (4) together with condition (4), we deduce that there exists a subsequence $\left\{x_{n(k)}\right\}$ of $\left\{x_{n}\right\}$ such that $\alpha\left(x_{n(k)}, x_{*}\right) \geq 1$ for all $k$. Applying (3), for all $k$, we get that

$$
\begin{aligned}
d\left(x_{n(k)+1}, T x_{*}\right) & =d\left(T x_{n(k)}, T x_{*}\right) \\
& \leq \alpha\left(x_{n(k)}, x_{*}\right) d\left(T x_{n(k)}, T x_{*}\right) \\
& \leq \beta\left(M\left(x_{n(k)}, x_{*}\right)\right) M\left(x_{n(k)}, x_{*}\right) .
\end{aligned}
$$

On the other hand, we have

$$
\begin{aligned}
M\left(x_{n}, x_{*}\right) & =\max \left\{d\left(x_{n}, x_{*}\right), d\left(x_{n}, T x_{n}\right), d\left(x_{*}, T x_{*}\right)\right\} \\
& =\max \left\{d\left(x_{n}, x_{*}\right), d\left(x_{n}, x_{n+1}\right), d\left(x_{*}, T x_{*}\right)\right\} .
\end{aligned}
$$

Letting $k \rightarrow \infty$ in the above equality, we get that

$$
\lim _{k \rightarrow \infty} M\left(x_{n(k)}, x_{*}\right)=d\left(x_{*}, T x_{*}\right) .
$$

Suppose that $d\left(x_{*}, T x_{*}\right)>0$. From (9), for $k$ large enough, we have $M\left(x_{n(k)}, x_{*}\right)>0$, which implies that $\beta\left(M\left(x_{n(k)}, x_{*}\right)\right)<M\left(x_{n(k)}, x_{*}\right)$. By Remark 2.1, we have

$$
d\left(x_{n(k)+1}, T x_{*}\right)<M\left(x_{n(k)}, x_{*}\right) .
$$

Letting $k \rightarrow \infty$ in the above inequality, using (9), we obtain that

$$
d\left(x_{*}, T x_{*}\right)<d\left(x_{*}, T x_{*}\right),
$$

a contradiction. Thus, we find $d\left(x_{*}, T x_{*}\right)=0$, that is, $x_{*}=T x_{*}$.

For the uniqueness of a fixed point of a generalized $\alpha$-Geraghty contractive mapping, we consider the following hypothesis.

(H) For all $x, y \in \operatorname{Fix}(T)$, there exists $z \in X$ such that $\alpha(x, z) \geq 1$ and $\alpha(y, z) \geq 1$.

Here, $\operatorname{Fix}(T)$ denotes the set of fixed points of $T$.

Theorem 2.3 Adding condition $(\mathrm{H})$ to the hypotheses of Theorem 2.1 (resp. Theorem 2.2), we obtain that $x_{*}$ is the unique fixed point of $T$. 
Proof Due to Theorem 2.1 (resp. Theorem 2.2), we have a fixed point, namely $x_{*} \in X$. Let $y_{*} \in X$ be another fixed point of $T$. Then, by assumption, there exists $z \in X$ such that

$$
\alpha\left(x_{*}, z\right) \geq 1 \quad \text { and } \quad \alpha\left(y_{*}, z\right) \geq 1
$$

Since $T$ is $\alpha$-admissible, from (10), we derive that

$$
\alpha\left(x_{*}, T^{n} z\right) \geq 1 \quad \text { and } \quad \alpha\left(y_{*}, T^{n} z\right) \geq 1 \quad \text { for all } n .
$$

Hence we have

$$
\begin{aligned}
d\left(x_{*}, T^{n} z\right) & \leq \alpha\left(x_{*}, T^{n-1} z\right) d\left(T x_{*}, T T^{n-1} z\right) \\
& \leq \beta\left(d\left(x_{*}, T^{n-1} z\right)\right) d\left(x_{*}, T^{n-1} z\right) \\
& <d\left(x_{*}, T^{n-1} z\right)
\end{aligned}
$$

for all $n \in \mathbb{N}$. Thus, the sequence $\left\{d\left(x_{*}, T^{n} z\right)\right\}$ is nonincreasing, and so there exists $u \geq 0$ such that $\lim _{n \rightarrow \infty} d\left(x_{*}, T^{n} z\right)=u$. From (12) we have

$$
\frac{d\left(x_{*}, T^{n} z\right)}{d\left(x_{*}, T^{n-1} z\right)} \leq \beta\left(d\left(x_{*}, T^{n-1} z\right)\right)
$$

and so $\lim _{n \rightarrow \infty} \beta\left(d\left(x_{*}, T^{n} z\right)\right)=1$. Consequently, we have $\lim _{n \rightarrow \infty} d\left(x_{*}, T^{n} z\right)=0$, and hence $\lim _{n \rightarrow \infty} T^{n} z=x_{*}$.

Similarly, we find that $\lim _{n \rightarrow \infty} T^{n} z=y_{*}$. Thus, we get $x_{*}=y_{*}$.

\section{Consequences}

We start this section with the following definition.

Definition 3.1 Let $(X, d)$ be a metric space, and let $\alpha: X \times X \rightarrow \mathbb{R}$ be a function. A map $T: X \rightarrow X$ is called $\alpha$-Geraghty contraction type map if there exists $\beta \in \mathcal{F}$ such that for all $x, y \in X$,

$$
\alpha(x, y) d(T x, T y) \leq \beta(d(x, y)) d(x, y) .
$$

Theorem 3.1 Let $(X, d)$ be a complete metric space, $\alpha: X \times X \rightarrow \mathbb{R}$ be a function, and let $T: X \rightarrow X$ be a map. Suppose that the following conditions are satisfied:

(1) $T$ is an $\alpha$-Geraghty contraction type map;

(2) $T$ is triangular $\alpha$-admissible;

(3) there exists $x_{1} \in X$ such that $\alpha\left(x_{1}, T x_{1}\right) \geq 1$;

(4) either $T$ is continuous or

$$
\lim _{n \rightarrow \infty} \inf \alpha\left(x_{n}, x\right)>0
$$

for any cluster point $x$ of a sequence $\left\{x_{n}\right\}$ with $\alpha\left(x_{n}, x_{n+1}\right) \geq 1$.

Then $T$ has a fixed point $x_{*} \in X$, and $\left\{T^{n} x_{1}\right\}$ converges to $x_{*}$. 
Theorem 3.2 Let $(X, d)$ be a complete metric space, $\alpha: X \times X \rightarrow \mathbb{R}$ be a function, and let $T: X \rightarrow X$ be a map. Suppose that the following conditions are satisfied:

(1) $T$ is an $\alpha$-Geraghty contraction type map;

(2) $T$ is triangular $\alpha$-admissible;

(3) there exists $x_{1} \in X$ such that $\alpha\left(x_{1}, T x_{1}\right) \geq 1$;

(4) if $\left\{x_{n}\right\}$ is a sequence in $X$ such that $\alpha\left(x_{n}, x_{n+1}\right) \geq 1$ for all $n$ and $x_{n} \rightarrow x \in X$ as $n \rightarrow \infty$, then there exists a subsequence $\left\{x_{n(k)}\right\}$ of $\left\{x_{n}\right\}$ such that $\alpha\left(x_{n(k)}, x\right) \geq 1$ for all $k$.

Then $T$ has a fixed point $x_{*} \in X$, and $\left\{T^{n} x_{1}\right\}$ converges to $x_{*}$.

Theorem 3.3 Adding condition $(\mathrm{H})$ to the hypotheses of Theorem 3.1 (resp. Theorem 3.2), we obtain that $x_{*}$ is the unique fixed point of $T$.

Remark 3.1 We show that the interesting result of Geraghty [6], Theorem 1.1, is a consequence of Theorem 3.1 and Theorem 3.3. Indeed, let $\alpha(x, y)=1$ for all $x, y \in X$. Then $T$ is an $\alpha$-Geraghty contraction type map. It is evident that all the hypotheses of Theorem 3.1 and Theorem 3.3 are satisfied. Hence, $T$ has a unique fixed point.

Corollary 3.4 [3] Let $(X, \preceq)$ be a partially ordered set and suppose that there exists a metric $d$ on $X$ such that $(X, d)$ is a complete metric space. Suppose that $T: X \rightarrow X$ is a map. Assume that the following conditions are satisfied:

(1) there exists $\beta \in \mathcal{F}$ such that

$$
d(T x, T y) \leq \beta(d(x, y)) d(x, y)
$$

for all $x, y \in X$ with $y \preceq x$;

(2) there exists $x_{1} \in X$ such that $x_{1} \preceq T x_{1}$;

(3) $T$ is increasing;

(4) either $T$ is continuous or if $\left\{x_{n}\right\}$ is an increasing sequence with $\lim _{n \rightarrow \infty} x_{n}=x$, then $x_{n} \preceq x$ for all $n \in \mathbb{N}$.

Then $T$ has a fixed point $x_{*} \in X$, and $\left\{T^{n} x_{1}\right\}$ converges to $x_{*}$. Further if, for any $x, y \in X$, there exists $z \in X$ such that $z$ is comparable to $x$ and $y$, then $T$ has a unique fixed point in $X$.

Proof Define a function $\alpha: X \times X \rightarrow[0, \infty)$ by

$$
\alpha(x, y)= \begin{cases}1 & \text { if } x \preceq y \\ 0 & \text { otherwise }\end{cases}
$$

Then from (1) we have $\alpha(x, y) d(T y, T x) \leq \beta(d(y, x)) d(y, x)$ for all $x, y \in X$, and so (13) is satisfied.

Hence, the condition (1) of Theorem 3.1 is fulfilled. Since $T$ is increasing, $\alpha(x, y)=1$ implies $\alpha(T x, T y)=1$ for all $x, y \in X$. Thus, $T$ is triangular $\alpha$-admissible.

Condition (2) implies that there exists $x_{1} \in X$ such that $\alpha\left(x_{1}, T x_{1}\right)=1$, and so condition (3) of Theorem 3.1 is satisfied.

Condition (4) implies that condition (4) of Theorem 3.1 is satisfied. 
Thus, all the conditions of Theorem 3.1 are satisfied. By Theorem 3.1, $T$ has a fixed point in $X$.

We give an example to illustrate Theorem 3.1.

Example 3.1 Let $X=[0, \infty)$, and let $d(x, y)=|x-y|$ for all $x, y \in X$. Let $\beta(t)=\frac{1}{1+t}$ for all $t \geq 0$. Then it is clear that $\beta \in \mathcal{F}$.

We define a mapping $T: X \rightarrow X$ by

$$
T x= \begin{cases}\frac{1}{2} x & (0 \leq x \leq 1) \\ 2 x & (x>1)\end{cases}
$$

and a function $\alpha: X \times X \rightarrow[0, \infty)$ by

$$
\alpha(x, y)= \begin{cases}1 & (0 \leq x, y \leq 1) \\ 0 & \text { otherwise }\end{cases}
$$

Condition (3) of Theorem 3.1 is satisfied with $x_{1}=1$. Condition (4) of Theorem 3.1 is satisfied with $x_{n}=T^{n} x_{1}=\frac{1}{n}$.

Let $x, y \in X$ such that $\alpha(x, y) \geq 1$.

Then $x, y \in[0,1]$, and so $T x \in[0,1], T y \in[0,1]$ and $\alpha(T x, T y)=1$. Hence $T$ is $\alpha$ admissible, and hence (2) is satisfied.

We show that the condition (1) of Theorem 3.1 is satisfied.

If $0 \leq x, y \leq 1$, then $\alpha(x, y)=1$, and we have

$$
\begin{aligned}
\beta(d(x, y)) d(x, y)-\alpha(x, y) d(T x, T y) & =\beta(d(x, y)) d(x, y)-d(T x, T y) \\
& =\frac{|x-y|}{1+|x-y|}-\frac{1}{2}|x-y| \\
& =\frac{|x-y|(1-|x-y|)}{2(1+|x-y|)} \\
& \geq 0 .
\end{aligned}
$$

Hence, for $0 \leq x, y \leq 1, \alpha(x, y) d(T x, T y) \leq \beta(d(x, y)) d(x, y)$.

If $0 \leq x \leq 1$ and $y>1$, then $\alpha(x, y)=0$, and we have $\alpha(x, y) d(T x, T y) \leq \beta(d(x, y)) d(x, y)$.

Thus, all the hypotheses of Theorem 3.1 are satisfied, and $T$ has a fixed point $x_{*}=0$.

Note that (2) is not satisfied. In fact, for $x=1, y=2$, we have

$$
d(T 1, T 2)=\frac{7}{2}>\frac{1}{2}>\beta(d(2,1)) d(2,1) .
$$

\section{Application to ordinary differential equations}

We consider the following two-point boundary value problem of a second-order differential equation:

$$
\left\{\begin{array}{l}
-\frac{d^{2} x}{d t^{2}}=f(t, x(t)), \quad t \in[0,1], \\
x(0)=x(1)=0
\end{array}\right.
$$

where $f:[0,1] \times \mathbb{R} \rightarrow \mathbb{R}$ is a continuous function. 
The Green function associated to (15) is given by

$$
G(t, s)= \begin{cases}t(1-s), & 0 \leq t \leq s \leq 1 \\ s(1-t), & 0 \leq s \leq t \leq 1\end{cases}
$$

Let $C(I)$ be the space of all continuous functions defined on $I$, where $I=[0,1]$, and let $d(x, y)=\|x-y\|_{\infty}=\sup _{t \in I}|x(t)-y(t)|$ for all $x, y \in C(I)$.

Then $(C(I), d)$ is a complete metric space.

Let $\phi:[0, \infty) \rightarrow[0, \infty)$ be a function satisfying the following conditions:

(1) $\phi$ is increasing;

(2) for each $t>0, \phi(t)<t$;

(3) $\beta(t)=\frac{\phi(t)}{t} \in \mathcal{F}$.

As examples of such functions, we can list the following $\phi(t)=\frac{t}{1+t}$ and $\phi(t)=\ln (1+t)$.

We consider the following conditions:

(a) there exists a function $\xi: \mathbb{R}^{2} \rightarrow \mathbb{R}$ such that for all $t \in I$, for all $a, b \in \mathbb{R}$ with $\xi(a, b) \geq 0$, we have

$$
|f(t, a)-f(t, b)| \leq \phi(|a-b|)
$$

(b) there exists $x_{1} \in C(I)$ such that for all $t \in I$,

$$
\xi\left(x_{1}(t), \int_{0}^{1} G(t, s) f\left(s, x_{1}(s)\right) d s\right) \geq 0
$$

(c) for all $t \in I$ and for all $x, y \in C(I)$,

$$
\xi(x(t), y(t)) \geq 0 \quad \text { implies } \quad \xi\left(\int_{0}^{1} G(t, s) f(s, x(s)) d s, \int_{0}^{1} G(t, s) f(s, y(s)) d s\right) \geq 0
$$

(d) for any cluster point $x$ of a sequence $\left\{x_{n}\right\}$ of points in $C(I)$ with $\xi\left(x_{n}, x_{n+1}\right) \geq 0$, $\lim _{n \rightarrow \infty} \inf \xi\left(x_{n}, x\right) \geq 0$.

Theorem 4.1 Suppose that conditions (a)-(d) are satisfied. Then (15) has at least one solution $x^{*} \in C^{2}(I)$.

Proof It is known that $x \in C^{2}(I)$ is a solution of (15) if and only if $x \in C(I)$ is a solution of the integral equation

$$
x(t)=\int_{0}^{1} G(t, s) f(s, x(s)) d s \quad \text { for all } t \in I
$$

We define $T: C(I) \rightarrow C(I)$ by

$$
T x(t)=\int_{0}^{1} G(t, s) f(s, x(s)) d s \quad \text { for all } t \in I \text {. }
$$

Then problem (15) is equivalent to finding $x^{*} \in C(I)$ that is a fixed point of $T$. 
Let $x, y \in C(I)$ such that $\xi(x(t), y(t)) \geq 0$ for all $t \in I$. From (a) we have

$$
\begin{aligned}
|T x(t)-T y(t)| & =\left|\int_{0}^{1} G(t, s)[f(s, x(s))-f(s, y(s))] d s\right| \\
& \leq \int_{0}^{1} G(t, s)|f(s, x(s))-f(s, y(s))| d s \\
& \leq \int_{0}^{1} G(t, s) \phi(|x(s)-y(s)|) d s \\
& \leq \sup _{t \in I} \int_{0}^{1} G(t, s) d s \phi\left(\|x-y\|_{\infty}\right) \\
& =\frac{1}{8} \frac{\phi(d(x, y))}{d(x, y)} d(x, y) \\
& <\beta(d(x, y)) d(x, y) .
\end{aligned}
$$

Thus we have $d(T x, T y)<\beta(d(x, y)) d(x, y)$ for all $x, y \in C(I)$ such that $\xi(x(t), y(t)) \geq 0$ for all $t \in I$.

We define $\alpha: C(I) \times C(I) \rightarrow[0, \infty)$ by

$$
\alpha(x, y)= \begin{cases}1 & \text { if } \xi(x(t), y(t)) \geq 0, t \in I \\ 0 & \text { otherwise }\end{cases}
$$

Then, for all $x, y \in C(I)$, we have

$$
\alpha(x, y) d(T x, T y)<\beta(d(x, y)) d(x, y) .
$$

Obviously, $\alpha(x, y)=1$ and $\alpha(y, z)=1$ implies $\alpha(x, z)=1$ for all $x, y, z \in C(I)$.

If $\alpha(x, y)=1$ for all $x, y \in C(I)$, then $\xi(x(t), y(t)) \geq 0$. From (c) we have $\xi(T x(t), T y(t)) \geq 0$, and so $\alpha(T x, T y)=1$. Thus, $T$ is triangular $\alpha$-admissible.

From (b) there exists $x_{1} \in C(I)$ such that $\alpha\left(x_{1}, T x_{1}\right)=1$.

By (d), we have that for any cluster point $x$ of a sequence $\left\{x_{n}\right\}$ of points in $C(I)$ with $\alpha\left(x_{n}, x_{n+1}\right)=1, \lim _{n \rightarrow \infty} \inf \alpha\left(x_{n}, x\right)=1$.

By applying Theorem 2.1, $T$ has a fixed point in $C(I)$, i.e., there exists $x^{*} \in C(I)$ such that $T x^{*}=x^{*}$, and $x^{*}$ is a solution of (15).

\section{Competing interests}

The authors declare that there is no conflict of interests regarding the publication of this article.

\section{Authors' contributions}

All authors contributed equally and significantly in writing this article. All authors read and approved the final manuscript.

\section{Author details}

${ }^{1}$ Department of Mathematics, Hanseo University, Chungnam, 356-706, South Korea. ${ }^{2}$ Department of Mathematics,

Moyngji University, Yongin, 449-728, South Korea. ${ }^{3}$ Department of Mathematics, Atilim University, Ankara, 06836, Turkey.

\section{Acknowledgements}

The authors thank anonymous reviewers for their remarkable comments, suggestion and ideas that helped to improve our paper.

Received: 19 August 2013 Accepted: 7 November 2013 Published: 03 Dec 2013 


\section{References}

1. Banach, S: Sur les operations dans les ensembles abstraits et leur applications aux equations integrales. Fundam. Math. 3, 133-181 (1922)

2. Rhoades, BE: A comparison of various definitions of contractive mappings. Trans. Am. Math. Soc. 226, 257-290 (1977)

3. Amini-Harandi, A, Emami, H: A fixed point theorem for contraction type maps in partially ordered metric spaces and applications to ordinary differential equations. Nonlinear Anal. 72, 2238-2242 (2010)

4. Agarwal, RP, El-Gebeily, MA, O'Regan, D: Generalized contractions in partially ordered metric spaces. Appl. Anal. 87, 1-8 (2008)

5. Cho, $\mathrm{SH}, \mathrm{Bae}, \mathrm{JS}$ : Common fixed point theorems for mappings satisfying property (E.A) on cone metric spaces. Math. Comput. Model. 53, 945-951 (2011)

6. Geraghty, M: On contractive mappings. Proc. Am. Math. Soc. 40, 604-608 (1973)

7. Hille, E, Phillips, RS: Functional Analysis and Semi-Groups. Amer. Math. Soc. Colloq. Publ., vol. 31. Am. Math. Soc., Providence (1957)

8. Huang, LG, Zhang, X: Cone metric spaces and fixed point theorems of contractive mappings. J. Math. Anal. Appl. 332(2), 1468-1476 (2007)

9. Khamsi, MA, Kreinovich, VY: Fixed point theorems for dissipative mappings in complete probabilistic metric spaces. Math. Jpn. 44, 513-520 (1996)

10. Yang, SK, Bae, JS, Cho, SH: Coincidence and common fixed and periodic point theorems in cone metric spaces. Comput. Math. Appl. 61, 170-177 (2011)

11. Caballero, J, Harjani, J, Sadarangani, K: A best proximity point theorem for Geraghty-contractions. Fixed Point Theory Appl. 2012, Article ID 231 (2012)

12. Samet, B, Vetro, C, Vetro, P: Fixed point theorems for $\alpha$ - $\psi$-contractive type mappings. Nonlinear Anal. 75, $2154-2165$ (2012)

13. Karapinar, E, Kumam, P, Salimi, P: On $\alpha$ - $\psi$-Meir-Keeler contractive mappings. Fixed Point Theory Appl. 2013, Article ID 94 (2013)

14. Karapinar, E, Samet, B: Generalized $(\alpha-\psi)$-contractive type mappings and related fixed point theorems with applications. Abstr. Appl. Anal. 2012, Article ID 793486 (2012)

10.1186/1687-1812-2013-329

Cite this article as: Cho et al.: Fixed point theorems for $\alpha$-Geraghty contraction type maps in metric spaces. Fixed Point Theory and Applications 2013, 2013:329

\section{Submit your manuscript to a SpringerOpen ${ }^{\ominus}$ journal and benefit from:}

- Convenient online submission

- Rigorous peer review

- Immediate publication on acceptance

- Open access: articles freely available online

- High visibility within the field

- Retaining the copyright to your article 